\title{
O Perfil da Disciplina Contabilidade Rural nas Universidades Federais Brasileiras: Uma Análise Após Adoção do CPC 29/IAS 41
}

\section{The Profile of the Discipline Rural Accounting in the Brazilian Federal Universities: An Analysis After Adoption of CPC 29/IAS 41}

\author{
Thaís da Silva Rodrigues \\ Bacharel em Ciências Contábeis pela UNIR \\ thais.srodrigues2016@gmail.com \\ Deyvison de Lima Oliveira \\ Doutor em Administração pela UFRGS
}

Professor do Departamento de Ciências Contábeis Universidade Federal de Rondônia (UNIR) deyvilima@gmail.com

José Arilson de Souza

Doutor em Desenvolvimento Regional pela UNIR

Professor do Departamento de Ciências Contábeis Universidade Federal de Rondônia (UNIR) professorarilson@hotmail.com

Elder Gomes Ramos

Mestre em Administração pela FEAD/MG

Professor do Departamento de Ciências Contábeis Universidade Federal de Rondônia (UNIR)

\section{RESUMO}

elder.gomes@unir.br

Com a edição do Pronunciamento CPC 29, altera-se o método de mensuração de ativos biológicos, surgindo demandas para alterações também no ensino da Contabilidade Rural, que é ramo da contabilidade com características específicas em assuntos relacionados à avaliação e mensuração dos ativos biológicos e produtos agrícolas. O objetivo desta pesquisa é identificar o perfil da disciplina Contabilidade Rural nas universidades federais brasileiras entre 2015 e 2016. Para isso, empregou-se abordagem descritiva com aspecto qualitativo, do tipo documental. Foram realizadas análises dos planos de ensino e dos projetos pedagógicos do curso de Ciências Contábeis de 30 universidades federais dentro do universo de 40 instituições de ensino superior. Os resultados revelaram consideráveis variações no método de ensino, nomenclaturas da disciplina, conteúdos e referências. Para a denominação das disciplinas constataram-se, inicialmente, 13 nomenclaturas diferentes. Os conteúdos 'Ativo Biológico', 'CPC 29' e 'Método de mensuração a valor justo' foram abordados em apenas 25\% das universidades; assuntos ligados a 'atividade rural', 'planos de contas' e 'relatórios contábeis' são mais presentes nas ementas. Quanto às referências mais sugeridas, destaca-se as obras do autor Jose Carlos Marion, diferente do Pronunciamento Técnico CPC 29, que esteve presente em apenas quatro planos de ensino ou projetos pedagógicos. Tratando-se da metodologia, as instituições utilizam o método tradicional de ensino. A análise traz indícios de que conceitos e aplicações essenciais do CPC 29, especialmente, quanto à mensuração e evidenciação de ativos biológicos e produtos agrícolas, estão fora dos planos de ensino e ementas dos cursos de Contabilidade.

Palavras-chave: Contabilidade Rural; Ensino Superior; Universidades Federais. 


\begin{abstract}
With the publication of the Pronouncement CPC 29, the method of measurement of biological assets is modified, appearing demands for changes also in the teaching of Rural Accounting that is branch of financial accounting with specific characteristics in subjects related to the evaluation and measurement of biological assets and agricultural products. The objective of this research is to identify the profile of the discipline Rural Accounting in the Brazilian federal universities between 2015 and 2016. For that, a descriptive approach with a qualitative aspect of the document type was used. Analyzes of the teaching plans and pedagogical projects of the course of Accounting of 30 federal universities within the universe of 40 institutions of higher education were carried out. The results revealed considerable variations in the teaching method, discipline nomenclatures, contents and references. As for the denomination of the disciplines, there were initially 13 different nomenclatures. The contents 'Biological Asset', 'CPC 29' and 'Measurement method at fair value' were addressed in only $25 \%$ of the universities; the subjects related to 'rural activity', 'unit of accounts' and 'accounting reports' are more present in the plans. Regarding the most suggested references, we highlight the references of the author Jose Carlos Marion, different of the CPC 29 standard that was present in only four teaching plans or pedagogical project. And when it comes to methodology, institutions use the traditional method of teaching. The analysis provides indications that the essential concepts and applications of CPC 29, especially regarding the measurement and disclosure of biological assets and agricultural products, are outside the teaching plans and pedagogical projects in the accounting courses.
\end{abstract}

Keywords: Rural Accounting; Higher Education; Federal Universities.

\title{
1 INTRODUÇÃO
}

A Contabilidade Rural é o ramo da Contabilidade aplicada às empresas rurais que exercem atividades que exploram a capacidade produtiva do solo (MARION, 2014). Verificase, no contexto da Contabilidade Rural, uma especificidade na abordagem de assuntos que compreendem a avaliação dos ativos biológicos e dos produtos agrícolas e na organização das atividades, desde a evidenciação desses ativos até a apuração de lucros e prejuízos.

O setor rural é, assim, marcado pela entrada e saída, ora de bens, ora de serviços. Estabelece-se, desse modo, um intercâmbio entre o produtor e o consumidor final, em um processo que inclui a aquisição de matéria prima, o consumo, a produção, os insumos e a elaboração de relatórios contábeis do processo produtivo e das vendas. A representatividade do agronegócio no cenário econômico, no contexto internacional, tem demonstrado uma crescente demanda pelas commodities agrícolas. Nos últimos anos, os índices de exportações no setor, de venda total, no país, passaram de 36,8\%, em 2006, para 47,0\%, em 2015 (BACEN, 2016).

Em virtude desse aumento expressivo na produtividade rural e do câmbio favorável, em 2015, a participação do agronegócio no Produto Interno Bruto (PIB) do Brasil foi de 21,46\%, o que confirma o constante crescimento e fortalecimento do setor agrícola, mesmo em um contexto de instabilidade política e crise econômica (Centro de Estudos Avançados em Economia Aplicada - CEPEA/ESALQ-USP, 2016). Dados consolidados de 2017 mostram que essa representatividade do PIB do agronegócio chegou a 22\% do PIB brasileiro, sendo cerca de $5,4 \%$ do PIB total referente ao segmento do agronegócio dentro da porteira (agropecuária), que abrange a produção de ativos biológicos e produtos agrícolas variados (CEPEAESALQ/USP, 2019). O setor tem também recebido tratamento especial pela Contabilidade, levando em conta suas especificidades e seus atributos significativos para a evidenciação das 
demonstrações contábeis em nível internacional (BARROS et al., 2012). Isso constitui um reconhecimento da importância desse setor para a economia.

Considerando a necessidade de acompanhar a tendência internacional e estabelecer critérios para a unificação de procedimentos contábeis específicos para contabilização adequada dos ativos biológicos, em 2001, foi aprovada, pelo órgão normativo International Accounting Standards Board (IASB), a primeira norma internacional de contabilidade, denominada "IAS 41 - Agriculture". Essa norma estabeleceu o valor justo como critério apropriado para a mensuração de ativos biológicos e de produtos agrícolas (SILVA; MACHADO; MACHADO, 2013; GANASSIN; RODRIGUES; BORGES, 2016). No Brasil, o processo de adesão das normas brasileiras às Normas Internacionais de Contabilidade (IFRS) resultou na edição do Pronunciamento Técnico CPC 29, que versa especificamente sobre o conceito e a mensuração de ativo biológico, correlacionado ao Pronunciamento IAS 41 (FIGUEIRA; RIBEIRO, 2015).

Em relação à aplicabilidade do CPC 29, estudos têm revelado que existe uma diversidade de procedimentos, principalmente quanto à mensuração e à evidenciação dos ativos biológicos pelas empresas listadas na B3, conforme mostram as pesquisas de Barros et al. (2012), Figueira e Ribeiro (2015) e Cunha Silva et al. (2013). Em pesquisas realizadas nas principais bases de dados brasileiras na Coordenação de Aperfeiçoamento de Pessoal de Nível Superior (Periódicos da CAPES) e Scientífic Periodicals Eletronic Library (SPELL), constatou-se que não existem estudos voltados para a análise de como as instituições de ensino superior têm incorporado as novas mudanças normativas que envolvem a mensuração e a evidenciação de ativos biológicos nos currículos dos cursos de Ciências Contábeis, uma vez que a nova norma transformou significativamente a essência da mensuração contábil e demanda mudanças no ensino da Contabilidade Rural.

Diante do cenário produtivo e do processo de convergência contábil no setor de agronegócio pelos quais passa o Brasil, o objetivo geral desta pesquisa é analisar o perfil da disciplina de Contabilidade Rural nas universidades federais brasileiras, nos cursos de Ciências Contábeis, entre 2015 e 2016. Os objetivos específicos são os seguintes: a) analisar a grade curricular das universidades federais brasileiras, observando a oferta da disciplina de Contabilidade Rural; b) identificar os conteúdos programáticos adotados na ementa; c) identificar as principais referências utilizadas na disciplina; e d) verificar a metodologia de ensino da disciplina.

Além desta introdução, este artigo está estruturado em mais quatro seções. Na segunda seção é apresentado o referencial teórico. Na terceira seção consta o desenvolvimento metodológico da pesquisa. Os resultados são apresentados na seção quatro. Por último, a seção cinco apresenta as conclusões e recomendações do estudo.

\section{FUNDAMENTAÇÃO TEÓRICA}

Nesta seção, serão apresentadas (os): as diretrizes e sugestões para a elaboração do currículo do curso de Ciências Contábeis e para a disciplina de Contabilidade Rural que é vertente desta pesquisa; particularidades da Contabilidade Rural em relação a outras disciplinas e seus conceitos, incluindo as características e métodos de mensuração dos ativos biológicos de acordo com o CPC 29. Para o embasamento teórico, foram utilizadas principalmente, as seguintes fontes de informações: livros adotados reiteradamente no programa da disciplina, normas, artigos científicos em periódicos e em anais de congressos. Dentre os artigos científicos, foram utilizadas pesquisas em outros campos de ensino da contabilidade e sobre o estudo dos ativos biológicos e sua mensuração a valor justo. 


\subsection{Aspectos normativos do curso de Ciências Contábeis}

O Conselho Nacional de Educação e a Câmara de Educação Superior (CNE/CES), por meio da Resolução n. ${ }^{\circ}$ 10, de 16 de dezembro de 2004, instituíram as Diretrizes Curriculares Nacionais para o curso de Bacharelado em Ciências Contábeis, que visam à construção de um ensino adequado à formação dos futuros contadores. Em seu artigo 5. ${ }^{\circ}$, essa resolução estabelece os conteúdos para a harmonização das normas e dos padrões contábeis ao âmbito econômico e financeiro, nacional e internacional, da área. É necessário citar que a resolução não faz imposições ao currículo dos cursos - de fato, cabe a cada instituição de ensino definir quais disciplinas devem ser ministradas, bem como a carga horária a ser cumprida para cada conteúdo integralizado, desde que atenda aos conteúdos curriculares mínimos.

Já o Conselho Federal de Contabilidade (CFC), por meio da Portaria CFC n. ${ }^{\circ}$ 13/2006, elaborou uma Proposta Nacional de Conteúdos, que visa a apresentar os conceitos básicos para a estruturação do plano de ensino do curso de Ciências Contábeis, apresentando conteúdos programáticos, sugestões bibliográficas, carga horária e objetivos gerais das disciplinas. Essa Proposta Nacional de Conteúdos do CFC apresenta a Contabilidade Aplicada ao Agronegócio como disciplina optativa, com carga de 60 horas. A ementa estabelece o propósito de compreender a economia do Agronegócio e o fundamento das empresas relacionadas aos segmentos da Contabilidade Rural. A bibliografia apresentada como "básica", idealmente, deverá ser reformulada, atendendo à data da publicação da proposta e ao alinhamento das normas contábeis. A reformulação justifica-se devido às demandas atuais e específicas desse ramo aplicado ao controle patrimonial das entidades rurais.

\subsection{Mudança de paradigma na mensuração de ativos biológicos (CPC 29)}

A busca por procedimentos contábeis específicos para a contabilização adequada dos ativos biológicos levou, no ano de 2001, à aprovação, pelo órgão normativo internacional (IASB), da primeira Norma Internacional de Contabilidade, denominada "IAS 41 Agriculture". Essa norma estabeleceu o valor justo como critério apropriado para a mensuração de ativos biológicos e do produto agrícola (SILVA FILHO; MACHADO; MACHADO 2013; GANASSIN; RODRIGUES; BORGES, 2016). No Brasil, o alinhamento das normas brasileiras aos padrões internacionais relacionados ao IAS 41 aconteceu em 2009, por meio da edição do Pronunciamento CPC 29, que trata especificamente do reconhecimento, da mensuração e da evidenciação de tais ativos (FIGUEIRA; RIBEIRO, 2015).

Anteriormente, as entidades que exploravam atividades agrícolas e pecuárias eram regidas pela NBC-T 10.14 (entidades rurais), que estabelecia a mensuração dos ativos biológicos na medida da sua formação a custo histórico, reconhecendo o ganho (ou perda) nas demonstrações contábeis apenas no período em que ocorria a venda (BARROS et al., 2012).

Com a aplicabilidade do CPC 29, em conjunto com o CPC 46, foram estabelecidos os parâmetros necessários à evidenciação e à mensuração dos ativos biológicos e dos produtos agrícolas pelo valor justo (valor de mercado), menos a despesa da venda no momento do reconhecimento inicial, no final de cada período de competência e no momento da colheita (FIGUEIRA; RIBEIRO, 2015; BARRETO et al., 2016). Segundo o CPC 46, o valor justo é o valor contábil de saída, ou seja, o preço pelo qual um ativo pode ser pago ou um passivo, liquidado, em uma transação não forçada entre as partes interessadas na data de mensuração.

Ao contrário da normativa anterior (NBC-T 10.14), o CPC 29 apresenta os conceitos relacionados ao produto agrícola, definindo-o como o produto colhido ou, de alguma forma, obtido a partir de um ativo biológico de uma entidade. Os ativos biológicos referem-se a um animal e/ou uma planta, vivos, que sofrem transformação biológica para formar o produto 
agrícola (CPC, 2009). Assim sendo, o pronunciamento técnico é aplicado a ativos biológicos e para a produção de produtos agrícolas obtidos no momento e no ponto da colheita pelos ativos biológicos da entidade.

De acordo com o CPC 29, o reconhecimento dos ativos biológicos ou de produtos agrícolas ocorre quando e somente quando: a entidade possuir controle desses ativos, como resultado de eventos passados; os benefícios econômicos fluírem para sociedade; e sua mensuração a valor justo ou custo forem confiáveis. O pressuposto do CPC 29 é o de que, em todos os casos, o valor justo do produto agrícola é sempre possível de ser identificado no momento da colheita (OLIVEIRA; OLIVEIRA, 2017). Somente quando não houver mercado ativo e/ou ativos biológicos similares para a mensuração de forma confiável do seu valor justo, aplica-se a mensuração pelo valor de custo, deduzindo qualquer depreciação e perda por irrecuperabilidade acumulada. No entanto, o reconhecimento pelo custo ocorre apenas no momento inicial, pois, tornando-se possível a mensuração do ativo biológico ao seu valor justo, a entidade passará a utilizá-la imediatamente (CPC, 2009).

\subsection{Particularidades da Contabilidade Rural}

De forma específica, a Contabilidade Rural é nomeada pelo ramo da atividade em que está aplicada. Tem-se como exemplos a "Contabilidade Agrícola" ou a "Contabilidade Agrária”. O ramo agrícola está ligado às empresas rurais que exercem atividades capazes de explorar a capacidade produtiva do solo (MARION, 2014). Segundo Carneiro e Carneiro (1933), a expressão "Contabilidade Rural" apresenta uma das melhores definições para as diversas modalidades de empresas que praticam a cultura dos campos, por meio da criação de animais e da transformação de alguns produtos do campo, dando-lhes novos usos. Já a expressão "Contabilidade Agrícola", não veicula uma ideia clara da abrangência desse vasto ramo da ciência contábil.

Com o passar dos anos, a evolução socioeconômica e os avanços tecnológicos mudaram a fisionomia das propriedades rurais, levando, assim, à necessidade de uma nova abordagem para o setor agrícola. Reflexo desses novos tempos é o termo agribusiness, que chegou ao Brasil na década de 1980 e foi, desde então, utilizado no setor, tendo sido traduzido como "agronegócio" (ARAÚJO, 2007).

A Contabilidade Rural, ou Contabilidade de Agronegócio, pode ser considerada a vertente da Contabilidade que abrange os conceitos e a metodologia contábil para a mensuração do patrimônio e do resultado rural. Também abrange mais atividades, como a agroindústria e outras atividades zootécnicas e agrícolas, como a pecuária, desde a oferta de insumos, passando pelos segmentos porteira adentro (início) até pós-porteira (final). Assim, o agronegócio é aperfeiçoado por vários itens que geram o crescimento patrimonial da entidade rural, demonstrando especificidades em relação às características das demais empresas tipicamente urbanas (OLIVEIRA; OLIVEIRA 2017), como apresentado no Quadro 1.

Quadro 1- Especificidades da Contabilidade Rural

\begin{tabular}{|c|l|lc|c|}
\hline Tópicos & $\begin{array}{c}\text { Conteúdo da } \\
\text { disciplina }\end{array}$ & \multicolumn{1}{|c|}{ Descrição } & Fontes \\
\hline I & $\begin{array}{l}\text { Ciclo operacional } \\
\text { e exercício social }\end{array}$ & $\begin{array}{l}\text { O exercício social é definido pelo tempo do ciclo } \\
\text { operacional (da aquisição dos insumos ao recebimento da } \\
\text { venda dos produtos/ativos). Na atividade rural, esse ciclo } \\
\text { pode ultrapassar os 12 meses [comuns às demais } \\
\text { atividades produtivas]. Neste caso, os conceitos de } \\
\text { "circulante" "não circulante" devem obedecer ao tempo } \\
\text { do ciclo operacional. }\end{array}$ & $\begin{array}{c}\text { Oliveira } \\
(2014)\end{array}$ \\
\end{tabular}




\begin{tabular}{|c|c|c|c|}
\hline Tópicos & $\begin{array}{l}\text { Conteúdo da } \\
\text { disciplina }\end{array}$ & Descrição & Fontes \\
\hline II & $\begin{array}{l}\text { Reconhecimento } \\
\text { da transformação } \\
\text { biológica no } \\
\text { resultado do } \\
\text { exercício }\end{array}$ & $\begin{array}{l}\text { A transformação biológica envolve todo o processo de } \\
\text { maturação dos ativos biológicos provenientes de } \\
\text { crescimento, degeneração, produção e procriação dos } \\
\text { ativos biológicos e colheita de produtos agrícolas, sendo } \\
\text { reconhecidos como ganhos (ou perdas) no resultado do } \\
\text { exercício, mesmo sem a realização da venda. }\end{array}$ & $\begin{array}{c}\text { CPC (2009); } \\
\text { Oliveira e } \\
\text { Oliveira } \\
(2017)\end{array}$ \\
\hline III & $\begin{array}{l}\text { Mensuração pelo } \\
\text { valor de saída }\end{array}$ & $\begin{array}{l}\text { A mensuração do ativo biológico e do produto agrícola } \\
\text { deve ser realizada a valor justo menos a despesa de venda, } \\
\text { no momento da colheita do produto agrícola e no } \\
\text { reconhecimento inicial e no final de cada período de } \\
\text { competência do ativo biológico, tendo como base o valor } \\
\text { atribuído pelas condições atuais de mercado, ou seja, um } \\
\text { preço de saída na data de mensuração. }\end{array}$ & $\begin{array}{l}\text { CPC (2009); } \\
\text { CPC (2012); } \\
\text { Marion } \\
(2014) .\end{array}$ \\
\hline IV & $\begin{array}{c}\text { Reconhecimento } \\
\text { da degeneração } \\
\text { dos ativos } \\
\text { biológicos }\end{array}$ & $\begin{array}{l}\text { A degeneração dos ativos biológicos é provocada pela } \\
\text { redução da quantidade ou deterioração na qualidade da } \\
\text { planta ou do animal, sendo reconhecida pelo método a } \\
\text { valor justo como perdas (redução de valor do ativo) no } \\
\text { resultado do exercício, podendo ser comparada à figura da } \\
\text { depreciação no método de mensuração pelo custo, já que } \\
\text { corresponde ao desgaste efetivo pelo uso ou às perdas pelo } \\
\text { uso, visto que tanto uma como a outra são redutoras de } \\
\text { ativos na Contabilidade do Agronegócio. }\end{array}$ & $\begin{array}{l}\text { CPC (2009); } \\
\text { Martins et al } \\
\text { (2014); } \\
\text { Martins e } \\
\text { Oliveira } \\
\text { (2014); } \\
\text { Oliveira e } \\
\text { Oliveira } \\
\text { (2017) }\end{array}$ \\
\hline $\mathbf{V}$ & $\begin{array}{c}\text { Resultado } \\
\text { econômico e } \\
\text { realizado }\end{array}$ & $\begin{array}{l}\text { O resultado econômico representa o resultado advindo do } \\
\text { confronto entre ganhos, perdas e despesas na mensuração a } \\
\text { valor justo de ativos biológicos e de produtos agrícolas que } \\
\text { ainda constam no Balanço Patrimonial até o momento que } \\
\text { antecede a venda. Assim, o resultado será realizado } \\
\text { somente quando os produtos ou ativos forem transferidos } \\
\text { para terceiros, ou seja, no momento em que ocorrer a } \\
\text { receita de venda, o resultado se realizará financeiramente. }\end{array}$ & $\begin{array}{c}\text { Oliveira e } \\
\text { Oliveira } \\
(2017)\end{array}$ \\
\hline VI & $\begin{array}{l}\text { Fluxo contábil na } \\
\text { atividade agrícola }\end{array}$ & $\begin{array}{l}\text { Quanto à atividade agrícola, a classificação contábil } \\
\text { subordina-se à qualidade dos grupos de ativos biológicos. } \\
\text { Os ativos consumíveis (culturas temporárias) são os } \\
\text { colhidos como produto agrícola ou vendidos como ativos } \\
\text { biológicos. Os ativos para a produção (culturas } \\
\text { permanentes) utilizam-se de ativos biológicos para a } \\
\text { produção, que são tidos como "fornecedores" de produtos } \\
\text { agrícolas, mas não podem ser colhidos como tal, como por } \\
\text { exemplo é o caso de árvores frutíferas, das quais é colhido } \\
\text { o fruto. }\end{array}$ & $\begin{array}{l}\text { CPC (2009); } \\
\text { Marion } \\
(2014) ; \\
\text { Oliveira e } \\
\text { Oliveira } \\
(2017)\end{array}$ \\
\hline VII & $\begin{array}{l}\text { Contabilidade da } \\
\text { pecuária }\end{array}$ & $\begin{array}{l}\text { É aplicada às empresas pecuárias, que se dividem na } \\
\text { criação de gado e de animais que vivem em coletividade, } \\
\text { podendo ser eles bovinos, suínos, equinos e ovinos, entre } \\
\text { outros. O processo produtivo destinado à pecuária de corte } \\
\text { subdivide-se em três etapas: cria, recria e engorda. A } \\
\text { contabilização do rebanho, para apuração de resultado, } \\
\text { será realizada pelo método a valor justo. Só poderá ser } \\
\text { usado o método de custo quando não se obtiver } \\
\text { confiabilidade na determinação do valor justo. }\end{array}$ & $\begin{array}{c}\text { CPC (2009); } \\
\text { Marion } \\
(2014) .\end{array}$ \\
\hline
\end{tabular}




\begin{tabular}{|c|c|c|c|}
\hline Tópicos & $\begin{array}{l}\text { Conteúdo da } \\
\text { disciplina }\end{array}$ & Descrição & Fontes \\
\hline VIII & $\begin{array}{l}\text { Tributação na } \\
\text { atividade rural }\end{array}$ & $\begin{array}{l}\text { As pessoas jurídicas que exploram a atividade rural } \\
\text { sujeitam-se às regras de incidência do Imposto de Renda } \\
\text { (inclusive adicional) e da Contribuição Social sobre o } \\
\text { Lucro, aplicáveis às demais empresas, podendo } \\
\text { determinar, com base no enquadramento no lucro real, } \\
\text { presumido ou arbitrado. Adicionalmente, as empresas } \\
\text { rurais estão sujeitas ao diferimento do IR e da CSL sobre o } \\
\text { resultado econômico. }\end{array}$ & $\begin{array}{l}\text { Marion } \\
(2014) ; \\
\text { Oliveira e } \\
\text { Oliveira } \\
(2017) .\end{array}$ \\
\hline
\end{tabular}

Fonte: Elaborada com base nas diretrizes do CPC 29 e em Marion (2014), Martins et al (2014), Martins e Oliveira (2014) e Oliveira e Oliveira (2017).

Em relação às etapas de transformação e crescimento do patrimonio rural, especificamente, dos ativos biológicos, é importante respeitar as exigências do CPC 29, considerando as peculiaridades de cada cultura, a criação e a região para as informações contábeis (BARROS et al., 2012; SILVA; MARTINS; MACHADO 2013). Os itens identificados acima auxiliarão na compreensão e na análise da abordagem das particularidades ministradas pelas instituições de ensino superior nos conteúdos aplicados para o ensino da disciplina de Contabilidade Rural.

\subsection{Ensino de Contabilidade: perfis de disciplinas no Brasil}

$\mathrm{Na}$ pesquisa realizada, voltada para o ensino da disciplina Contabilidade de Agronegócio e Contabilidade Rural, entre 2009 e 30 de setembro de 2016, foram utilizadas como palavras-chave as seguintes expressões nos principais portais de periódicos científicos (CAPES e SPELL): "Contabilidade Rural", "Contabilidade de Agronegócio", "Ensino Superior" e "Universidades Federais". Constatou-se um número reduzido de estudos publicados sobre esses tópicos. Assim, algumas pesquisas que abordaram outras áreas da Contabilidade voltadas ao ensino superior foram consultadas para fundamentar esta pesquisa. Entre os estudos relevantes encontrados, ressalta-se a pesquisa de Sobra et al. (2015), que analisou o perfil da disciplina Contabilidade de Custos nas universidades brasileiras, a partir da estrutura dos planos de ensino, conteúdos abordados, referências adotadas, métodos de ensino e formas avaliativas.

$\mathrm{Na}$ pesquisa de Faria e Leal (2016), o estudo das ementas das disciplinas de Contabilidade Gerencial estava voltado para a análise do nível de adesão aos conteúdos aplicados dos Institutos de Ensino Superior (IES) de Minas Gerais à luz do Currículo Mundial (CM) e da Proposta Nacional apresentada pelo CFC.

Entre os estudos que analisaram os ativos biológicos e sua mensuração a valor justo estão as pesquisas de Barros et al. (2012), Martins, Machado e Callado (2013), Silva, Martins e Machado (2013), Oliveira, Cruz e Pinheiro (2014), Ganassin, Rodrigues e Borges (2016). Esses autores examinaram a aplicabilidade dos métodos de mensuração usados nas empresas da B3. Essas pesquisas realizadas nos diversos segmentos do agronegócio têm demonstrado a relevância desta abordagem para o contexto rural brasileiro.

E, paralelamente às pesquisas supracitadas, o objetivo deste estudo conceitua desde o levantamento das informações estruturadas em cada tópico até o objetivo geral, com base nos planos de ensino, nas ementas e nos projetos pedagógicos do curso.

Elaborado com base no cenário do novo padrão contábil (CPC 29) e considerando as particularidades da Contabilidade Rural, o modelo conceitual da pesquisa é apresentado na Figura 1. 
Como esquematizado na Figura 1, o modelo conceitual fornece uma visão geral da pesquisa, que visa identificar o perfil da disciplina de contabilidade rural com base nos planos de ensino, ementas e nos projetos pedagógicos do curso. Para tanto, analisa os conteúdos apresentados pelas universidades federais quanto ao seu alinhamento diante das normativas atuais da contabilidade de ativos biológicos (CPC 29 e normas correlatas). Os conceitos (particularidades) foram tratados na revisão de literatura (seção 2) e os resultados são apresentados na seção 4.

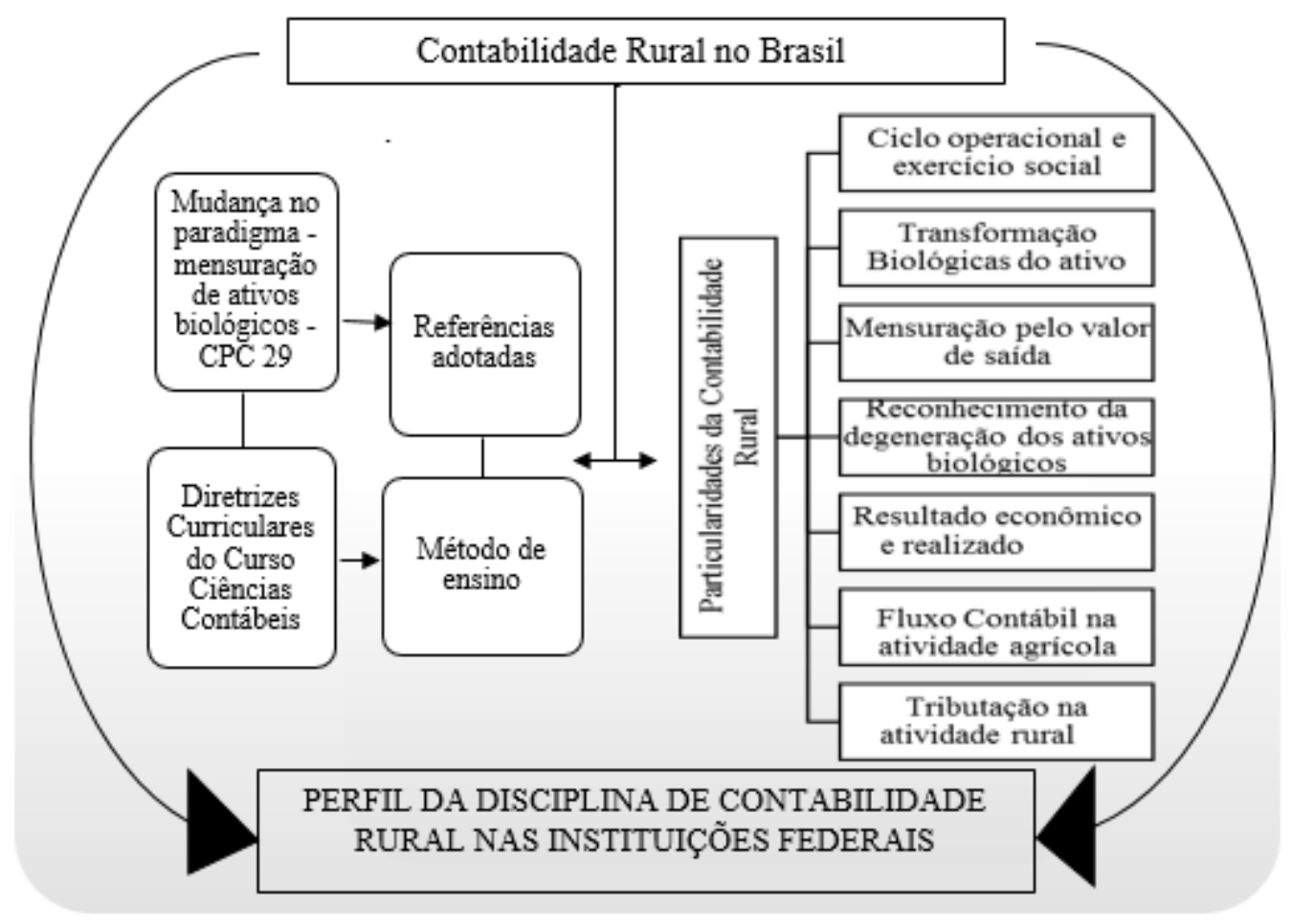

FIGURA 1 - Modelo conceitual de pesquisa Fonte: Elaborada pela pesquisadora

\section{PROCEDIMENTOS METODOLÓGICOS}

Para identificar o perfil da disciplina Contabilidade Rural nas Universidade Federais brasileiras, a pesquisa adotou procedimentos documentais, especificamente, a análise dos planos de ensino e/ou projetos pedagógicos do curso de Ciências Contábeis.

Assim, fazem parte da pesquisa as Universidades Federais que ofertam o curso e que disponibilizaram os planos de ensino da disciplina e/ou o projeto pedagógico do curso em algum meio (site ou $e$-mail).

Desta forma, a coleta de dados foi realizada em todas as Universidades Federais no Brasil que ofertam o curso de graduação em Ciências Contábeis de forma presencial, o que perfez o conjunto de 40 instituições (Vide apêndice A), segundo o levantamento realizado na plataforma do Ministério da Educação e Cultura ( $e$-MEC). Posteriormente, foram realizadas investigações nos websites institucionais das universidades, considerando que a unidade de análise da presente pesquisa é constituída pela ementa da disciplina (projeto pedagógico) e pelo plano de ensino nessas universidades.

Foram também enviados e-mails, entre os meses de novembro de 2016 e março de 2017, para a diretorias e/ou aos coordenadores dos cursos de Ciências Contábeis das universidades, com o objetivo de obter os documentos necessários para o prosseguimento da 
pesquisa. Algumas das universidades apresentam mais de um polo ou campus em cidades distintas. Assim, foram utilizados para análise o plano de ensino da disciplina ou o projeto pedagógico do curso (PPC).

Para os casos em que não foram fornecidos os planos de ensino por e-mail, mas foram obtidos o plano e o projeto pelo site, considerou-se o mais recente. Foram, então, obtidas nove ementas nos websites institucionais e outras nove por meio dos PPCs. Doze instituições de ensino forneceram-nas por e-mail, totalizando 30 universidades para a análise. Todas elas estão categorizadas no apêndice A como "ementa disponível".

Para o tratamento dos dados coletados, adotou-se o software Microsoft Excel de modo a analisar os elementos dos planos de ensino utilizados nas categorias de análise, definidas $a$ priori e apresentadas na Figura 1.

Especificamente, com base nos planos de ensino e nas ementas (projetos pedagógicos) são analisadas as nomenclaturas predominantes adotadas para a disciplina nas instituições, os conteúdos principais abordados na disciplina e a respectiva análise do alinhamento dos conteúdos ao padrão contábil internacional (IAS 41/CPC 29). Adicionalmente, são analisadas as principais referências bibliográficas adotadas para a disciplina nas instituições e a (des) atualização dessas referências, além dos procedimentos metodológicos predominantes na disciplina.

\section{RESULTADO E DISCUSSÃO}

Nesta seção, os resultados são apresentados e analisados conforme os objetivos propostos, a partir do tratamento dos dados fornecidos pelas instituições e coletados nos websites.

\subsection{Instituições federais de ensino superior}

Das 40 universidades investigadas, 30 delas forneceram os projetos pedagógicos e/ou planos de ensinos para análise, o que representa $75 \%$ das universidades federais existentes no país que ofertam o curso de Ciências Contábeis. Pode-se observar, na Tabela 1, que a composição das universidades é bem diversificada, estando presentes todas as regiões do país.

Tabela 1 - Agrupamento das universidades federais por região

\begin{tabular}{|c|c|c|c|c|c|}
\hline Região & Centro Oeste & Nordeste & Norte & Sudeste & Sul \\
\hline \multirow[t]{9}{*}{ Universidade Federal } & UnB & UFBA & UNIR & UFU & UFSM \\
\hline & UFG & UFAL & UFRR & UFSJ & FURG \\
\hline & UFMT & UFPE & UFAM & UFVJM & UTFPR \\
\hline & UFMS & UFS & UFT & UFJF & \\
\hline & & UFC & UNIFESSPA & UFMG & \\
\hline & & UFMA & UFRA & UFES & \\
\hline & & UFPI & UFPA & UFRRJ & \\
\hline & & UFRN & & & \\
\hline & & UFERSA & & & \\
\hline Total & 4 & 9 & 7 & 7 & 3 \\
\hline
\end{tabular}

Fonte: Elaborada pelos autores com base no website das universidades.

Entre as universidades citadas, 15 delas apresentaram ementas com um número reduzido de pontos relacionados ao conteúdo, à programação da disciplina, aos objetivos e às metodologias adotadas, o que dificultou o acompanhamento do perfil da Contabilidade Rural. A maioria das universidades (17 instituições de ensino superior - IES) oferece a disciplina de 
Contabilidade Rural com uma carga horária de 60 horas; as demais ofertam-na com 51 a 90 horas-aula.

A disciplina, geralmente, é ministrada entre o quarto e o oitavo período do curso. A análise da grade curricular apresentou os seguintes resultados: em 13 universidades, a disciplina aparece como de caráter obrigatório; em 17, como optativa. Em relação às instituições que ministram a disciplina, 17 disponibilizaram a disciplina na grade curricular. As demais informaram apenas o nome 'Contabilidade Rural' (ou equivalente), sem informar o período ministrado ou apresentar a expressão "disciplina optativa" ou sem mencionar o nome da disciplina adotada.

\subsection{Análise dos planos de ensino e projetos pedagógicos do curso}

Conforme esquematizado pela Figura 2, buscou-se, inicialmente verificar as nomenclaturas utilizadas para as disciplinas ofertadas pelas universidades que abordam em sua estrutura conteúdos relacionados à Contabilidade Rural.

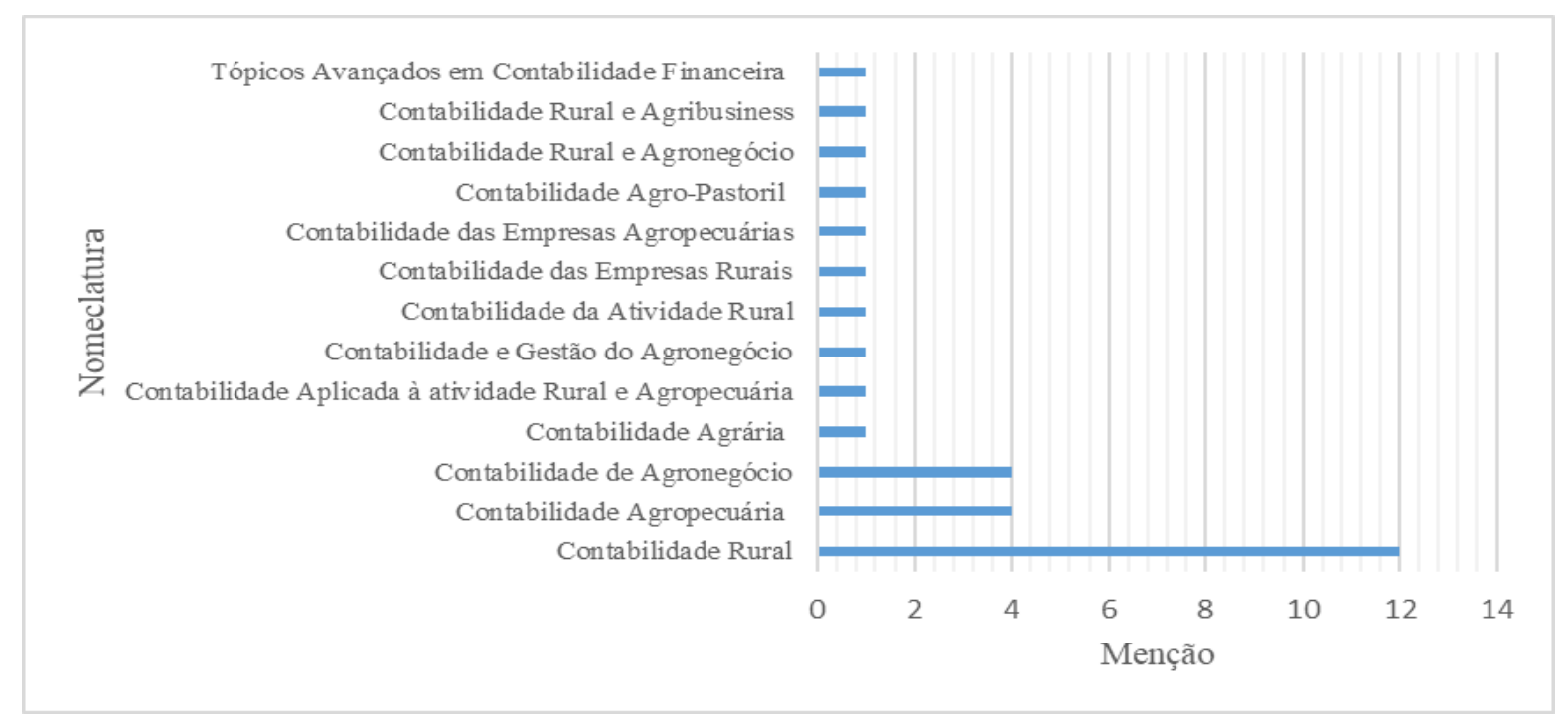

FIGURA 2. Denominação da disciplina nas diferentes universidades

Fonte: Elaborada pelos autores com base em dados da pesquisa.

É possível identificar que a nomenclatura mais comum adotada pelas universidades foi a de "Contabilidade Rural", com 12 menções entre as 30 instituições analisadas. Contudo, outras 12 denominações foram identificadas, o que correspondeu a uma parcela de $60 \%$ das menções obtidas. Assim, os dados relativos à nomenclatura da disciplina são diversificados, revelando a pluralidade entre as universidades.

\subsubsection{Conteúdo apresentado}

Os conteúdos ministrados na disciplina estão evidenciados na Tabela 2.

Tabela 2 - Conteúdos aplicados pelas universidades federais

\begin{tabular}{lcc}
\hline Conteúdo da disciplina & Menção & \% \\
\hline 1. Atividade Rural & 27 & 96,43 \\
2. Plano de Contas & 23 & 82,14 \\
3. Relatórios Contábeis do Agronegócio & 22 & 78,57 \\
4. Fluxo Contábil na atividade agrícola & 18 & 64,29 \\
5. Desvalorização dos ativos & 18 & 64,29 \\
6. Aspectos legais e fiscais das empresas rurais & 16 & 57,14
\end{tabular}




\begin{tabular}{lcc} 
7. Custos de operação & 16 & 57,14 \\
8. Contabilidade na Pecuária & 12 & 42,86 \\
9. Ativo Biológico (CPC 29) & 8 & 28,57 \\
10. Método de mensuração a Custo histórico & 8 & 28,57 \\
11. Método de mensuração a Valor justo & 7 & 25,00 \\
12. Projetos agropecuários e os gastos com melhorias & 7 & 25,00 \\
13. Demonstração do Fluxo de Caixa na atividade Rural & 3 & 10,71 \\
\hline
\end{tabular}

Fonte: Elaborada pelos autores com base em dados da pesquisa.

Duas universidades ficaram fora da análise por apresentarem ementas com assuntos muito amplos, como "Contabilidade Rural", "Contabilidade no Agronegócio", "Contabilização dos fatos", o que tornou inviável a categorização desses termos.

Com base nos resultados, constata-se que apenas os tópicos "Atividade Rural", "Planos de Contas" e "Relatórios Contábeis do Agronegócio" tiveram uma menção de mais de 75\%. Os conteúdos "Fluxo Contábil da atividade agrícola" e "Desvalorização dos ativos" obtiveram uma menção de mais de 64\%. "Custo na operação" e "Aspectos legais e fiscais das empresas rurais" constam de 57,14\% das ementas e a "Contabilidade na Pecuária", de 42,86\%. Com exceção da "Contabilidade na Pecuária", esses assuntos não foram levantados no Quadro 1, entretanto, os resultados encontrados demonstram a relevância deles no projeto de curso das universidades. Quanto aos conteúdos relativos a Ativo Biológico e CPC 29, observa-se que há reduzida menção pelas universidades. De fato, somente oito instituições inseriram o CPC 29 como item de conteúdo na disciplina de Contabilidade Rural.

Diante dos preceitos do CPC 29 quanto à mensuração e às divulgações relacionadas aos ativos biológicos e aos produtos agrícolas, consideráveis modificações na forma de contabilização desses ativos foram demandadas nas entidades e também no ensino da contabilidade. Por exemplo, como regra, a mensuração dos ativos biológicos é pelo valor justo e não mais pelo custo, como era a prática antes de 2010. Segundo o item 30 do CPC 29, o método do custo histórico deve ser usado para os casos em que o valor justo não possa ser mensurado de forma confiável.

E, tratando-se dos métodos de mensuração de ativos biológicos e de produtos agrícolas nos projetos e planos da disciplina nas universidades, constata-se que a abordagem a eles é relativamente reduzida. A mensuração a valor justo esteve presente em apenas sete $(25 \%)$ das 28 ementas e nos planos de ensinos analisados. Por uma pequena diferença, o método de mensuração pelo custo histórico foi mais mencionado pelas universidades analisadas, embora seja a exceção na mensuração de ativos biológicos - conforme item 30 do CPC 29.

Outra abordagem que apresentou resultado reduzido foi a Demonstração dos Fluxos de Caixa. Essa demonstração, quando aplicada à atividade rural, apresenta características peculiares, que a diferenciam das atividades de segmentos comerciais e industriais, principalmente, nas transações que envolvem os grupos "Estoque" e "Imobilizado", sendo um instrumento importante para analisar e avaliar as informações nas atividades do agronegócio (OLIVEIRA; OLIVEIRA, 2017). Nesta pesquisa, houve somente três menções a essa demonstração nas ementas das instituições.

As demonstrações contábeis aplicadas à produção de ativos biológicos apresentam diferenciais decorrentes dos temas/conteúdos apresentados no quadro de particularidades, sendo, portanto, efeitos dos conteúdos abordados na Tabela 2. Assim, essas demonstrações foram desconsideradas no objetivo geral da pesquisa, sendo oportunas investigações que as considerem nas suas especificidades. É possível citar, como exemplo, as especificidades dos "Planos de contas", que tratam das técnicas de elaboração e operacionalização da planificação contábil e da classificação no Balanço Patrimonial e na Demonstração de Resultado do Exercício, que foram abordados na Tabela 2. 
Assim, com base na comparação dos conteúdos aplicados pelas universidades e tópicos levantados na literatura (seção 2.3), com os materiais pesquisados para o resultado, constata-se que as ementas têm se concentrado em temáticas relacionadas à tributação e a abordagens do método de custo na mensuração de ativos biológicos, ao passo que a regra do padrão internacional (IAS 41/CPC 29) é a mensuração desses ativos pelo valor justo. Outros assuntos citados como sendo particularidades no referencial, a exemplo do "Ciclo operacional", "Resultado econômico", "Degeneração do ativo biológico" mensurado a valor justo e "Reconhecimento da transformação biológica no resultado do exercício" não foram categorizados nas ementas e nos planos de ensinos. Tais resultados podem se justificar pelo número reduzido de citação, nas ementas, do CPC 29, e pelo fato de muitas obras adotadas demonstrarem omissão no tratamento da mensuração a valor justo. Este levantamento será apresentado no tópico a seguir.

\subsubsection{Referências adotadas}

Em relação às bibliografias sugeridas, foram verificados 22 planos de ensino e suas respectivas referências básicas ou complementares para o ensino da disciplina, sendo que oito universidades não apresentaram quaisquer referências. No total, contabilizaram-se 85 referências. Devido ao volume de dados, foram considerados no ranking (Tabela 3 ) apenas as obras/autores ou normativas que obtiveram três ou mais menções nos planos de ensino. As citações estão apresentadas na Tabela 3, que expõe os resultados pela quantidade mencionada e sua representatividade nas 22 instituições.

Constata-se que a principal obra adotada, com $91 \%$ das citações, foi a do autor José Carlos Marion, intitulada Contabilidade Rural. Outras duas obras foram mencionadas com relativa frequência, sendo elas Contabilidade da Pecuária, com aproximadamente $45 \%$ das ocorrências e Administração de custos na agropecuária, com 40,91\% do total das menções. As obras Contabilidade rural: uma abordagem decisorial, de Crepaldi, Agronegócio, de Callado, Fundamentos de agronegócios, de Araújo, e Contabilidade do Agronegócio, de Oliveira, obtiveram 15 , sete, seis e seis menções, respectivamente.

Tabela 3- Principais referências adotadas nos planos de ensinos

\begin{tabular}{|c|c|c|}
\hline Referência & Menções & $\%$ \\
\hline $\begin{array}{l}\text { MARION, J. C. Contabilidade rural: contabilidade agrícola, contabilidade da pecuária e } \\
\text { imposto de renda pessoa jurídica. São Paulo: Atlas. }\end{array}$ & 20 & 90,91 \\
\hline CREPALDI, S. A. Contabilidade rural: uma abordagem decisorial. São Paulo: Atlas. & 15 & 68,18 \\
\hline $\begin{array}{l}\text { MARION, J. C; Segatti, S. Contabilidade da Pecuária: atualizada pelas Leis } \\
11.638 / 2007 \text { e } 11.941 / 09 \text {. São Paulo: Atlas. }\end{array}$ & 14 & 45,45 \\
\hline $\begin{array}{l}\text { SANTOS, G. J. D.; MARION, J. C; SEGATTI, S. Administração de custos na } \\
\text { agropecuária. São Paulo: Atlas. }\end{array}$ & 9 & 40,91 \\
\hline CALLADO, A. A. C. Agronegócio. São Paulo: Atlas. & 7 & 31,82 \\
\hline ARAUJO, M. J. Fundamentos de agronegócios. São Paulo: Atlas. & 6 & 27,27 \\
\hline $\begin{array}{l}\text { OLIVEIRA, N. C. Contabilidade do Agronegócio: teoria e prática. Curitiba: Juruá } \\
\text { Editora. }\end{array}$ & 6 & 27,27 \\
\hline ANCELES, P. E. D. S. Manual de tributos da atividade rural. São Paulo: Atlas. & 4 & 18,18 \\
\hline BATALHA, M. O. Gestão agroindustrial. São Paulo: Atlas. & 4 & 18,18 \\
\hline $\begin{array}{l}\text { CPC } 29 \text { Ativo Biológico e Produto Agrícola. Comitê de Pronunciamentos Contábeis. } \\
2009 .\end{array}$ & 4 & 18,18 \\
\hline NEPOMUCENO, F. Contabilidade Rural e seus Custos de Produção. São Paulo/ IOB. & 4 & 18,18 \\
\hline VALLE, F. Manual de contabilidade agrária. São Paulo: Atlas. & 4 & 18,18 \\
\hline $\begin{array}{l}\text { OLIVEIRA, D. L; OLIVEIRA, G. D. Contabilidade rural: uma abordagem do } \\
\text { agronegócio dentro da porteira. Curitiba: Juruá Editora. }\end{array}$ & 3 & 13,64 \\
\hline
\end{tabular}

Fonte: Elaborada pelos autores com base em dados da pesquisa. 
Merece atenção o resultado relacionado à referência do Pronunciamento CPC 29. Esse documento foi mencionado por apenas quatro instituições, sinalizando que as universidades, em sua maioria, não estariam adotando a nova normativa no ensino da disciplina. Trata-se de uma constatação que merece atenção das instituições, considerando a relevância do Pronunciamento e as mudanças significativas que este padrão contábil provocou.

Observa-se que a Contabilidade Rural possui uma literatura mais restrita em comparação a outros setores da Contabilidade. Muitas referências adotadas pelas universidades estão desatualizadas ou foram mesmo revogadas (no caso das normas!). Com base nessa informação, a Tabela 4 condensa o levantamento da defasagem das obras, obtida por meio da subtração do ano de publicação dos PPCs pela média simples dos anos de publicação das obras. Três universidades não informaram o ano das obras adotadas.

Tabela 4 -Desatualização das obras adotadas

\begin{tabular}{|c|c|c|c|c|c|}
\hline $\begin{array}{c}\text { Desatualização } \\
\text { (em anos) }\end{array}$ & IES & $\begin{array}{c}\text { Ano do } \\
\text { Plano/Projeto }\end{array}$ & $\begin{array}{c}\text { Desatualização } \\
\text { (em anos) }\end{array}$ & IES & $\begin{array}{c}\text { Ano do } \\
\text { Plano/Projeto }\end{array}$ \\
\hline \multirow{5}{*}{ De 16 a 11} & UFES & 2007 & \multirow{10}{*}{ De 5 a 1} & UFRR & 2009 \\
\hline & UFRA & 2012 & & UFERSA & 2011 \\
\hline & UFT & 2015 & & UFMA & 2012 \\
\hline & UFMS & 2016 & & UFG & 2012 \\
\hline & UFVJM & 2016 & & UFAL & 2013 \\
\hline \multirow{5}{*}{ De 10 a 6} & UFU & 2007 & & UFBA & 2016 \\
\hline & UFRRJ & 2014 & & UFJF & 2016 \\
\hline & UFSM & 2014 & & UTFPR & 2016 \\
\hline & UFMT & 2015 & & UnB & 2016 \\
\hline & UNIR & 2016 & & & \\
\hline
\end{tabular}

Fonte: Elaborada pelos autores com base em dados da pesquisa.

Verificou-se que 53\% das universidades $(n=10)$ usam referências que foram publicadas há mais de seis anos. Muitas dessas obras não possuem edições mais recentes e há universidades que não atualizaram seus planos de ensino ou PPCs. Há instituições cujas referências apresentam desatualização de mais de 11 anos, o que explica o fato de não utilizarem obras que abordem assuntos sobre a mensuração de ativos biológicos a valor justo, já que o CPC 29 foi editado em 2009.

Diante desses achados, é visível a necessidade de atualizar/reformular os projetos pedagógicos das instituições, tendo em vista o estágio atual de convergência aos padrões contábeis internacionais, fomentada pela criação do CPC em 2005 e pela promulgação das Leis n. $^{\circ} 11.638 / 07$ e 11.941/09.

\subsubsection{Métodos de ensino}

As instituições de ensino superior possuem autonomia para elaborarem e fixarem os currículos de seus cursos e estabelecerem suas metodologias de ensino dentro das normas vigentes. A análise identificou que apenas sete universidades apresentaram estratégias de ensino e apenas seis especificaram seus instrumentos pedagógicos. Nove universidades disponibilizaram informações sobre o método de avaliação/pontuação.

Dentre as sete universidades que mencionaram a metodologia de ensino, seis delas adotam aulas expositivas e três universidades realizam atividades em sala e extraclasse, debates e estudos de caso. Uma universidade utiliza portfólio como estratégia de ensino.

Em relação aos instrumentos pedagógicos, cinco universidades usam instrumentos de multimídia e apenas uma não menciona utilização do quadro branco. Duas universidades informaram os recursos 'livros e revistas científicas' para o ensino. Os métodos de avaliação 
apresentaram menos variações, pois todas as universidades analisadas utilizam a prova como critério de avaliação. Seis instituições também recorrem a trabalhos e a exercícios práticos; quatro universidades cobram a elaboração de seminários e apenas uma menciona a resenha de artigos científicos em seu plano de ensino.

Dados os resultados acima, verifica-se certa semelhança entre os métodos adotados para o ensino em sala de aula, com destaque para Universidade Federal de Mato Grosso (UFMT) que usa a operação da fazenda experimental em sua metodologia. Entende-se que algumas universidades não possuem estrutura para ofertar atividade em campo ou acesso a profissionais e ambientes que atuam no processamento das atividades rurais. Porém, sendo possível ofertar atividades extraclasses para o aprendizado, os alunos poderão vivenciar os conceitos apresentados em aula e identificar com maior desempenho as particularidades da contabilidade rural levantadas nesta pesquisa.

Constata-se que as metodologias adotadas são similares àquelas da pesquisa de Sobra et al. (2015), que analisou o perfil da disciplina de contabilidade de custo em 18 universidades. Tal pesquisa também apresenta certa regularidade nos métodos de ensino e traz como um dos itens importantes para o desenvolvimento acadêmico, o método avaliativo, tendo esta pesquisa $100 \%$ de menção ao processo avaliativo. De forma quantitativa, não generalizada, pode-se verificar que as universidades seguem um padrão em seus métodos de ensino.

\section{CONCLUSÕES E RECOMENDAÇÕES}

O objetivo geral da pesquisa foi analisar o perfil da disciplina Contabilidade Rural nas universidades federais brasileiras, nos cursos de Ciências Contábeis, entre 2015 e 2016. Os objetivos específicos da pesquisa foram: a) analisar a grade curricular das universidades federais brasileiras, observando a oferta da disciplina Contabilidade Rural; b) identificar os conteúdos programáticos adotados na ementa; c) identificar as principais referências utilizadas na disciplina; e d) verificar a metodologia de ensino da disciplina. Utilizou-se como material de análise os planos de ensinos e os PPCs de 30 instituições, que forneceram suas ementas através dos websites ou por e-mails.

Inicialmente, foi possível constatar a dificuldade por parte dos discentes ou da comunidade acadêmica em acompanhar os elementos adotados para ensino da disciplina, pois metade das universidades analisadas não apresentaram informações detalhadas em seus planos de ensino, ementas ou projetos pedagógicos do curso (PPC). Muitas ementas foram analisadas com as informações contidas no projeto pedagógico. Sabendo-se que tal documento é editado com menos frequência, se comparado ao plano de ensino, é razoável a ausência de conteúdos atualizados sobre o CPC 29. Contudo, cabe a cada instituição atentarse quanto ao tempo de atualização, considerando que os PPCs servem de parâmetro para o ensino.

Predominantemente, a disciplina tem carga horária de 60 horas-aulas e é oferecida em caráter optativo, apresentando ainda uma diversidade de nomenclaturas correspondentes ao ensino da Contabilidade Rural. Quanto à análise dos conteúdos aplicados, demonstrou-se que apenas os assuntos relacionados a "Atividade rural", "Planos de contas", "Relatórios contábeis", "Fluxo Contábil na atividade agrícola", "Desvalorização dos ativos", "Aspectos legais e fiscais das empresas rurais" e "Custos de operação" tiveram abordagem maior que $50 \%$. Já os assuntos "Ativo biológico", "CPC 29", a mensuração a "valor justo" e pelo "custo histórico" obtiveram baixa citação nos planos de ensino.

A Contabilidade Rural passou por consideráveis modificações com a adoção do pronunciamento CPC 29 no Brasil a partir de 2010. Diante dos conteúdos aplicados pelas universidades desse estudo e considerando que as diretrizes curriculares são definidas e executadas com certo grau de liberdade pelas instituições, os achados demonstram que as 
particularidades da Contabilidade Rural previstas nas diretrizes do CPC 29, essencialmente quanto à mensuração e evidenciação de ativos biológicos e produtos agrícolas, estão ausentes na maioria dos planos de ensinos e ementas de Contabilidade Rural.

Para corroborar essa realidade, tem-se a constatação de que somente quatro IES mencionam o CPC 29 em suas referências. Cumpre observar, que os resultados levantados são analisados, principalmente, à luz do CPC 29, sendo que essa ausência de conteúdos específicos pode impactar a formação profissional e implicar em futuros problemas e divergências na mensuração e evidenciação de ativos das entidades, já que o processo de formação tem influência no exercício profissional.

Na perspectiva prática, a pesquisa contribui com os atores envolvidos no processo ensino-aprendizagem de Contabilidade (instituições de ensino, discentes, docentes, técnicos) ao trazer à tona o distanciamento entre os conteúdos ministrados na disciplina e o potencial conhecimento demandado no campo profissional, considerando a vigência do CPC 29 desde 2010 e sua aplicação pelas entidades do agronegócio e por profissionais contábeis, aliada à reduzida abordagem ao padrão contábil nas ementas da disciplina e às temáticas inerentes (mensuração de ativos biológicos, valor justo, evidenciação de ativos biológicos...). Nesta linha, os resultados também contribuem para evidenciar a necessidade de as instituições atualizarem as ementas e as referências da disciplina, com vistas a abordarem os padrões contábeis internacionais adotados no Brasil (e.g. CPC 29) no contexto da graduação.

Na perspectiva teórica, a pesquisa sinaliza para a necessidade de desenvolvimento ou aplicação de metodologias de ensino diferenciadas (não tradicionais) na disciplina, no intuito de promover a integração entre teoria e prática, especialmente, no tocante ao ensino dos processos de reconhecimento, mensuração e disclosure de ativos biológicos na graduação em Ciências Contábeis.

Como destacado, os resultados foram alcançados através da análise dos planos de ensino das universidades. Como principal limitação, destaca-se a análise das ementas coletadas nos projetos pedagógicos do curso, que apresentam número reduzido de elementos (e.g. conteúdos aplicados, objetivos, bibliografias e metodologias adotadas) - o que possibilita uma análise parcial do objetivo geral desta pesquisa. Embora a amostra abranja grande parte das Universidades Federais que oferecem o curso Ciências Contábeis (75\%), os resultados refletem a realidade da amostra no momento da pesquisa e não podem ser generalizados para todas as instituições que oferecem a disciplina.

Sugere-se a realização de pesquisas horizontais, com vistas à comparação do perfil da disciplina de Contabilidade Rural nas Universidades Federais com o de outras instituições de ensino superior, como as estaduais ou as privadas, buscando verificar possível evolução ou retrocessos no perfil da disciplina.

Outra sugestão envolve a consideração dos aspectos regionais para analisar e caracterizar os possíveis elementos econômicos e produtivos que explicam a distribuição de conteúdo e da carga horária, bem como a presença (ou não) da disciplina nos currículos dos cursos de Ciências Contábeis nas diversas regiões do país. Adicionalmente, é relevante uma análise com o corpo docente para possibilitar maior aprofundamento sobre a realidade de oferta da disciplina, tendo em vista a ausência de manuais divulgados pelos normatizadores nacionais e internacionais (CPC, CFC, IAS) para a interpretação do IAS 41 e a mensuração dos ativos biológicos a valor justo, o que poderia explicar parte das dificuldades em abordar os assuntos na graduação. 


\section{REFERÊNCIAS}

ARAUJO, M. J. Fundamento de Agronegócios. 2 ed. São Paulo: Atlas, 2005.

BACEN. Boletim Regional do Banco Central do Brasil, v. 10, n. 3. Disponível em: http://www.bcb.gov.br/pec/boletimregional/port/2016/07/br201607inp.pdf . Acesso em: 11 set. 2016.

BARRETO, A. A. R. et al. Piscicultura Integrada à Agroindústria: uma Proposta de Fluxo Contábil de Acordo com os CPCS 29 e 16. RACE: Revista de Administração, Contabilidade e Economia, v. 15, n. 3, p. 915-944, 2016. Disponível em: http://www.spell.org.br/documentos/ver/42905/piscicultura-integrada-a-agroindustria--umaproposta-de-fluxo-contabil-de-acordo-com-os-cpcs-29-e-16. Acesso em: 19 out. 2016.

BARROS, C. C. et al. O impacto do valor justo na mensuração dos ativos biológicos nas empresas listadas na BM\&FBOVESPA. Revista de Contabilidade do Mestrado em Ciências Contábeis da UERJ, v. 17, n. 3, p. 41-59, 2012. Disponível em: http://www.spell.org.br/documentos/ver/9333/o-impacto-do-valor-justo-na-mensuracao-dosativos-biologicos-nas-empresas-listadas-na-bm-fbovespa/i/pt-br. Acesso em: 9 set. 2016.

BRASIL, Presidência da República. Ministério da Educação. Resolução CNE/CSE n. ${ }^{\circ} 10$, de 16 de dezembro de 2004. Institui as Diretrizes Curriculares Nacionais para o Curso de Graduação em Ciências Contábeis, bacharelado. Disponível em:

http://portal.mec.gov.br/cne/arquivos/pdf/rces10_04.pdf. Acesso em: 20 ago. 2016.

CARNEIRO, J.; CARNEIRO, E. Tratado de Contabilidade V. 3. Contabilidade rural. 2. ed. BRASIL, 1933.

CEPEA/ESALQ-USP. PIB do Agronegócio - Dados de 1995 a 2015. 2016. Disponível em: http://cepea.esalq.usp.br/pib. Acesso em: 11 de set. 2016.

CEPEA/ESALQ-USP. PIB do agronegócio brasileiro. Disponível em: https://www.cepea.esalq.usp.br/br/pib-do-agronegociobrasileiro.aspx. Acesso em: 25 de Fev. 2019.

COMITÊ DE PRONUNCIAMENTOS CONTÁBEIS (CPC). CPC 29 Ativo Biológico e Produto Agrícola. Comitê de Pronunciamentos Contábeis. 2009. Disponível em: http://www.cpc.org.br/index.php. Acesso em: 24 abr. 2016.

CPC 46 Mensuração do Valor Justo. Comitê de Pronunciamentos Contábeis. 2012. Disponível em: http://www.cpc.org.br/index.php. Acesso em 24 abr. 2016.

FARIA, P. M. O.; LEAL, E. A. Análise da temática Contabilidade Gerencial na formação em Ciências Contábeis de IES mineiras à luz do Currículo Mundial e da Proposta Nacional do CFC/FBC. Revista de Educação e Pesquisa em Contabilidade, v. 10, n. 2, p. 163-180, 2016. Disponível em: http://www.spell.org.br/documentos/ver/41813/analise-da-tematicacontabilidade-gerencial-na-formacao-em-ciencias-contabeis-de-ies-mineiras-a-luz-docurriculo-mundial-e-da-proposta-nacional-do-cfc-fbc-/i/pt-br. Acesso em 18 ago. 2016. 
FBC. Proposta nacional de conteúdo para o curso de graduação em Ciências Contábeis. 2 ed. Brasília: Fundação Brasileira de Contabilidade, 2009. Disponível em: http://portalcfc.org.br/wordpress/wp-content/uploads/2013/01/proposta.pdf. Acesso em 22 ago. 2016.

FIGUEIRA, L. M.; RIBEIRO, M. S. Análise da evidenciação sobre a mensuração de ativos biológicos: antes e depois do CPC 29. Revista Contemporânea de Contabilidade, v. 12, n. 26, p. 73-98, 2015. Disponível em: http://www.spell.org.br/documentos/ver/39955/analise-daevidenciacao-sobre-a-mensuracao-de-ativos-biologicos--antes-e-depois-do-cpc-29/i/pt-br. Acesso em 21 abr. 2016.

GANASSIN, E.J.F., RODRIGUES, F.F., BORGES, T.J.G. Mensuração de Ativos Biológicos e a observância do IAS 41 na América do Sul. Revista Custos e @gronegócio on line, - v. 12, n. 2, Abr/Jun, 2016. Disponível em:

http://www.custoseagronegocioonline.com.br/numero2v12/OK\%2016\%20biologicos.pdf . Acesso em 21 out. 2016.

GIL, A. C. Métodos e Técnicas de Pesquisa Social. 6 ed. São Paulo: Atlas, 2010.

MARCONI, M. A.; LAKATOS, E. M. Fundamentos de metodologia científica. 5. ed. São Paulo: Atlas, 2003.

MARION, J. C. Contabilidade Rural: Contabilidade Agrícola, Contabilidade da Pecuária, Imposto de Renda - Pessoa Jurídica. 14 ed. São Paulo: Atlas, 2014.

MARTINS, A. S.; OLIVEIRA, D. L. Reconhecimento contábil da degeneração de ativos biológicos para a produção no cultivo de árvores frutíferas. Revista Contemporânea de Contabilidade, v. 11, n. 22, p. 73-94, 2014. Disponível em:

http://www.spell.org.br/documentos/ver/35525/relevancia-e-representacao-fidedigna-namensuracao-de-ativos-biologicos-a-valor-justo-por-empresas-listadas-na-bm-fbovespa/i/pt-br. Acesso em 15 jun. 2016.

MARTINS, E., GELBCKE, E. R., SANTOS, A \& IUDÍCIBUS. S. Manual de Contabilidade Societária: aplicável a todas as sociedades. 2 ed. São Paulo: Atlas, 2013.

MARTINS, V. G.; MACHADO, M. A. V.; CALLADO, A. L. C. Relevância e representação fidedigna na mensuração de ativos biológicos a valor justo por empresas listadas na BM\&FBovespa. Revista Contemporânea de Contabilidade, UFSC, Florianópolis, v.11, n.22, p. 163-188, 2014. Disponível em:

http://www.spell.org.br/documentos/ver/35521/reconhecimento-contabil-da-degeneracao-deativos-biologicos-para-a-producao-no-cultivo-de-arvores-frutiferas/i/pt-br. Acesso em 13 abr. 2016.

Ministério da Educação e Cultura. Instituições de Educação Superior e cursos cadastrados. Recuperado em 28 julho, 2016. Disponível em: https://emec.mec.gov.br/ies. Acesso em 11 abr. 2016.

OLIVEIRA, D. L.; OLIVEIRA, G. D. Contabilidade rural: uma abordagem do agronegócio dentro da porteira. 3 ed. Curitiba: Juruá, 2017. 
OLIVEIRA, N. G.; CRUZ, N. G.; PINHEIRO, L. E. T. Mensuração de ativos biológicos a valor justo: Um estudo realizado em empresas brasileiras listadas na BM\&FBOVESPA. XXI Congresso Brasileiro de Custos, Natal, RN, Brasil, 2014. Disponível em:

https://anaiscbc.emnuvens.com.br/anais/article/view/3839/3840. Acesso em 16 ago.1 2016.

SILVA FILHO, A. C. d. C.; MACHADO, M. A. V.; MACHADO, M. R. Custo histórico X valor justo: qual informação é mais value relevant na mensuração dos ativos biológicos?

Revista Custos e @gronegócio on line, v. 9, n. 2, 2013. Disponível em: http://www.custoseagronegocioonline.com.br/numero2v9/Custos\%20historicos.pdf. Acesso em 13 jun. 2016.

SILVA FILHO, A. C. d. C.; MARTINS, V. G.; MACHADO, A. V. M. Adoção do valor justo para os ativos biológicos: análise de sua relevância em empresas brasileiras. Revista Universo Contábil, v. 9, n. 4, p. 110-127, 2013. Disponível em:

http://proxy.furb.br/ojs/index.php/universocontabil/article/view/3552/2531. Acesso em 13 jun. 2016.

SOMBRA, A. M. M.; et al. Perfil da Disciplina de Contabilidade de Custos nas Universidades Brasileiras: uma Análise nos Cursos de Graduação em Ciências Contábeis. Revista Gestão Organizacional, v. 9, n. 1, p. 66-83, 2016. Disponível em: http://www.spell.org.br/documentos/ver/42415/perfil-da-disciplina-de-contabilidade-decustos-nas-universidades-brasileiras--uma-analise-nos-cursos-de-graduacao-em-cienciascontabeis-/i/pt-br. Acesso em 18 ago. 2016. 


\section{APÊNDICE A - Unidade de análise}

Tabela 05- Universidades Federais participantes do estudo

\begin{tabular}{|c|c|c|c|c|}
\hline Região & $\begin{array}{c}\text { Unidade } \\
\text { Federativa }\end{array}$ & Universidades Federais Brasileiras & Sigla & $\begin{array}{c}\text { Ementa } \\
\text { disponível }\end{array}$ \\
\hline Centro & DF & Universidade de Brasília & UnB & SIM* \\
\hline \multirow[t]{4}{*}{ Oeste } & MS & Universidade Federal da Grande Dourados & UFGD & NÃO \\
\hline & GO & Universidade Federal de Goiás & UFG & $\operatorname{SIM}^{* * *}$ \\
\hline & MT & Universidade Federal do Mato Grosso & UFMT & SIM* \\
\hline & MS & Universidade Federal de Mato Grosso do Sul & UFMS & SIM** \\
\hline \multirow[t]{11}{*}{ Nordeste } & $\mathrm{BA}$ & Universidade Federal da Bahia & UFBA & SIM** \\
\hline & PB & Universidade de Campina Grande & UFCG & NÃO \\
\hline & PB & Universidade Federal da Paraíba & UFPB & NÃO \\
\hline & $\mathrm{AL}$ & Universidade Federal de Alagoas & UFAL & $\operatorname{SIM}^{* * *}$ \\
\hline & $\mathrm{PE}$ & Universidade Federal de Pernambuco & UFPE & SIM* \\
\hline & SE & Universidade Federal de Sergipe & UFS & SIM* \\
\hline & $\mathrm{CE}$ & Universidade Federal do Ceará & UFC & $\operatorname{SIM}^{* * *}$ \\
\hline & MA & Universidade Federal do Maranhão & UFMA & $\mathrm{SIM}^{*}$ \\
\hline & PI & Universidade Federal do Piauí & UFPI & $\operatorname{SIM}^{* * *}$ \\
\hline & $\mathrm{RN}$ & Universidade Federal do Rio Grande do Norte & UFRN & $\mathrm{SIM}^{* *}$ \\
\hline & $\mathrm{RN}$ & Universidade Federal Rural do Semi-Árido & UFERSA & $\mathrm{SIM}^{* *}$ \\
\hline \multirow[t]{7}{*}{ Norte } & RO & Universidade Federal de Rondônia & UNIR & $\mathrm{SIM}^{* *}$ \\
\hline & $\mathrm{RR}$ & Universidade Federal de Roraima & UFRR & $\mathrm{SIM}^{* *}$ \\
\hline & $\mathrm{AM}$ & Universidade Federal do Amazonas & UFAM & SIM* \\
\hline & TO & Universidade Federal do Tocantins & UFT & $\mathrm{SIM}^{* * *}$ \\
\hline & PA & Universidade Federal do Sul e Sudeste do Pará & \multicolumn{2}{|c|}{ UNIFESSPASIM* } \\
\hline & PA & Universidade Federal Rural da Amazônia & UFRA & $\mathrm{SIM}^{* * *}$ \\
\hline & PA & Universidade Federal do Pará & UFPA & $\mathrm{SIM}^{* * *}$ \\
\hline \multirow[t]{11}{*}{ Sudeste } & MG & Universidade Federal de Uberlândia & UFU & $\operatorname{SIM}^{* *}$ \\
\hline & MG & Universidade Federal de São João del-Rei & UFSJ & $\mathrm{SIM}^{*}$ \\
\hline & MG & Universidade Federal dos Vales do Jequitinhonha e Mucuri & UFVJM & $\operatorname{SIM}^{* *}$ \\
\hline & MG & Universidade Federal de Juiz de Fora & UFJF & $\operatorname{SIM}^{* *}$ \\
\hline & MG & Universidade Federal de Minas Gerais & UFMG & $\mathrm{SIM}^{* *}$ \\
\hline & MG & Universidade Federal de Viçosa & UFV & NÃO \\
\hline & SP & Universidade Federal de São Paulo & UNIFESP & NÃO \\
\hline & ES & Universidade Federal do Espírito Santo & UFES & SIM* $^{*}$ \\
\hline & RJ & Universidade Federal do Rio de Janeiro & UFRJ & NÃO \\
\hline & RJ & Universidade Federal Fluminense & UFF & NÃO \\
\hline & RJ & Universidade Federal Rural do Rio de Janeiro & UFRRJ & SIM*** \\
\hline \multirow[t]{6}{*}{ Sul } & $\mathrm{SC}$ & Universidade Federal de Santa Catarina & UFSC & NÃO \\
\hline & $\mathrm{RS}$ & Universidade Federal de Santa Maria & UFSM & $\mathrm{SIM}^{* *}$ \\
\hline & $\mathrm{RS}$ & Universidade Federal do Rio Grande do Sul & UFRGS & NÃO \\
\hline & $\mathrm{RS}$ & Universidade Federal do Rio Grande & FURG & SIM $^{*}$ \\
\hline & PR & Universidade Tecnológica Federal do Paraná & UTFPR & $\operatorname{SIM}^{* *}$ \\
\hline & PR & Universidade Federal do Paraná & UFPR & NÃO \\
\hline
\end{tabular}

Fonte: Elaborada pela pesquisadora de acordo com a plataforma do MEC (2016) e dos sites das universidades federais. *Coletada no site; ** fornecida por e-mail; *** extraída do PPC. 